\title{
Los procesos de lectura y escritura en la inteligencia emocional
}

\author{
Fecha de recepción: 13 de octubre de 2011 - Aceptación: 23 de noviembre de 2011
}

\section{Germán Giraldo Ramírez}

\section{Resumen:}

La asociación entre la inteligencia emocional —como un conjunto de recursos inherentes al sujeto que facilitan su calidad de vida-y los procesos de lectura y escritura constituyen una indagación muy reciente que no alcanza investigaciones depuradas en diferentes contextos académicos. No existe una axiomática generadora de principios y metodologías, sino un conjunto de textos que vienen alcanzando un éxito editorial que llaman la atención de muchos investigadores en actividades específicas, como es el caso de la lectura y escritura de textos. En este escrito se exponen algunas experiencias de proyectos de investigación con estudiantes de Enfermería de la Facultad de Salud de la Universidad Santiago de Cali y estudiantes del Distrito de Agua Blanca de Santiago de Cali. Dichas experiencias se desarrollan en cinco preguntas de investigación así: 1. Lectura, escritura y conocimiento de sí mismo. 2. Los recursos del control emocional 3. Auto motivación lectura y escritura. 4. La apropiación de la empatía 5. La inteligencia interpersonal como apropiación de las disciplinas en la formación profesional.

\section{Abstract}

The association between emotional intelligence as a set of resources inherent to the individual and that facilitate his quality of life and the processes of reading and writing is a very recent questioning which does not reach refined investigations in different academic contexts. There is not an axiom that generates principles and methodologies, but a set of texts that have reached a bestseller status and that call the attention of many researchers in specific activities, such as text reading and writing. This paper presents some experiences of research projects with students of Nursing of the Faculty of Health of the Santiago de Cali University and students of the Agua Blanca District of Santiago de Cali. Such experiences are developed in five research questions as follows: 1. Reading, writing, and self-knowledge. 2. The resources of emotional control 3. Self-motivation, reading, and writing. 4 . The appropriation of empathy 5. Interpersonal intelligence as the appropriation of disciplines in vocational training.

\section{Palabras clave}

Inteligencia emocional, automotivación, auto dominio, empatia, inteligencia interpersonal.

\section{Keywords}

Emotional intelligence, Self-motivation, Self-control, Empathy, Interpersonal Intelligence 


\section{Lectura escritura y conocimiento de sí mismo}

El punto de partida de estos razonamientos es el reconocimiento del sujeto como un ser activo generador de cambios en sí mismo y en el grupo donde convive, se identifica y se reconoce en él (Maturana, 1998). El sujeto es capaz de asociarse para asumir el desarrollo de acuerdos donde él es reconocido, identificándose con otros y construyéndose a sí mismo y al grupo que le reconoce. Debido a ello, el reconocimiento se realiza mediante constantes intercambios textuales durante toda la existencia. En la medida que el grupo en el cual se inscribe crece, el sujeto va encontrando el sentido del mundo que habita y se va dibujando en él, y de esta forma logra reconocerse a sí mismo. Esta indagación sobre las motivaciones intrínsecas de la lectura y la producción de textos recoge el punto de vista de los jóvenes lectores en el contexto en que ellos intervienen, valorando sus hallazgos desde sus dimensiones internas, desde sus intereses y desde su afán por participar en los eventos que les corresponde vivir. Dentro de este marco ha de considerarse la necesidad de los humanos de comprender

\section{Reseña de autor \\ Germán Giraldo Ramírez (Colombia) \\ Universidad Santiago de Cali \\ gegilra10@hotmail.com}

Docente de dedicación exclusiva de la Universidad Santiago de Cali, Licenciado en educación de la Universidad del Quindío con Especialidad en Lingüística y Literatura del Instituto Caro y Cuervo, (Bogotá). Especialista en Desarrollo intelectual y Educación de la Universidad Santiago de Cali. Doctorado en Investigación Educativa de la Universidad de Sevilla (España). Director del proyecto de investigación Evaluación de un Programa de Comprensión y Producción Textual de la Universidad Santiago de Cali. Director del Grupo de Ciencias del lenguaje con registro Colciencias 0050319 Investigador de temas pedagógicos de diseño curricular, evaluación educativa y de competencias comunicativas. y producir textos, haciéndolos participar enunciativamente de diversas apuestas explicativas en las cuales los libros siempre constituyen una ventana para mirar por dónde nace o se oculta el sol.

Siguiendo este sendero argumentativo, se encuentra que la palabra leída se guarda en el cuerpo como un conjunto de textos que buscan sentido en la vida de quienes los quieren asumir para su entorno. Las enunciaciones suscitadas en los procesos de comprensión y producción textual son reinventadas, generando imágenes, consejos, invitaciones, declaraciones, argumentos, explicaciones, descripciones que se descubren en el interior de quien lee, como insospechadas ausencias; por ello, a partir de ahora, se sienten o piensan como propias, en la medida en que dan sentido al contexto de quien ha leído sus nuevos textos. En este contexto es cuando se reconoce la destreza de la mente para asociar lo leído con lo sabido, pues la mente asimila nuevos conocimientos sobre sí mismo, y sobre su yo en el mundo.

Gracias a la imagen y proyección que tiene el sujeto de sí mismo, éste encuentra motivaciones que le permiten vivir y convivir en el contexto en el que él se inscribe y en el que él interviene para asumirlo en su transformación (Habermans J, 1986). El aspecto que aquí interesa es el descubrimiento de sí mismo como un proceso de auto reflexión permanente en la vida de cada uno de los sujetos. La inteligencia intrapersonal apropia los textos para conocerlos y enriquecer los esquemas mentales con los que se descubre la identidad del sujeto (Goleman, 1995). Saber leer las emociones, tener la capacidad para reconocerlas, enfrentarlas y asumirlas, transformándolas 
en energía positiva, constituye la base sobre la que se construye la inteligencia intra-personal. Obsérvese el siguiente enunciado: Yo leo para construir más y mejores fantasías en las que todos me creen lo que soy (Miguel, Distrito Agua-blanca, Santiago de Cali, Colombia).

El análisis de la lectura y la escritura, como ejercicio de construcción en el conocimiento de sí mismo, muestra la apropiación de textos por parte de muchos jóvenes y su reinvención en la escritura. Esta idea pensada desde el punto de vista de la lingüística textual (Dijk, 1986), se puede traducir como la capacidad para textualizar mediante el lenguaje lo que ocurre en el interior del lector y la forma como interviene desarrollando imágenes y textos sobre el sujeto que lee. Estos textos mejorar el concepto de sí mismo y logra dinamizarse al definir planes y proponerse estimulantes acciones que contribuyen a obtener una nueva imagen de su ser y de su existir.

Las reflexiones anteriores, analizadas desde los textos de la inteligencia emocional, muestran el primer concepto: la inteligencia intrapersonal definida como la capacidad para establecer diferencias entre quedar atrapado por una emoción o saber que se está preso en ella. Es el reconocimiento de la emoción en el momento que se experimenta. Se hace uso de la inteligencia intrapersonal cuando se es poseedor de la habilidad para leer las emociones, generando enunciados sobre ellas en el momento en que éstas suceden. Ser diligente emocionalmente significa poder fijar la atención de manera progresiva sobre las experiencias emocionales, auto reflexión e investigación de la forma como se es invadido por diferentes eventos subjetivos. Los analistas la distinguen como "aten- ción libremente flotante" (Freud, 1976). El paciente construye una manera de abarcar todo lo que ocurre en su conciencia como un testigo desinteresado, a través de la escucha de recomendaciones que hacen los terapeutas para dominar sus propias reacciones, a través del conjunto de confesiones hechas por el paciente sumergido en la asociación libre.

La lectura de sí mismo es la primera habilidad de la inteligencia intrapersonal, es posible profundizar mucho más desde otras miradas sobre la importancia del conocimiento del sujeto, en la vida y su papel en la estructuración de la imagen de si mismo. Por ahora lo que interesa en este ensayo es aproximarse a lo que ocurre con el desarrollo intelectual de los sujetos al asumir los procesos de lectura y escritura. En la dimensión cognitiva de la mente humana, los esquemas mentales organizan toda la información sobre nosotros mismos. El conocimiento de sí mismo, a través de los esquemas mentales, hace que se valoren los pensamientos y se diferencien emociones y sentimientos (Bourdieu, 1998). Pero la inteligencia intrapersonal tiene además otras dimensiones o campos de acción que configuran la forma de pensar y sentir del sujeto. En la dimensión afectiva se realiza una valoración de lo que se es, así como en la dimensión conductual se racionalizan las experiencias dirigidas a la auto formación y a la capacidad de reconocerse y reconocer a los demás (Cava y Musilú, 2000). Tal es el caso con la llegada a la adolescencia, muchos niños y niñas suelen llevar un diario o un cuaderno de notas personales en los cuales se puede encontrar testimonio de lo anotado.

Los textos mencionados en el párrafo anterior son diarios íntimos, se escriben
La lectura de símismo es la primera habilidad de la inteligencia intrapersonal, es posible profundizar mucho más desde otras miradas sobre la importancia del conocimiento del sujeto, en la viday su papel en la estructuración de la imagen de si mismo. 
como una mezcla de pensamientos propios y apropiados del mundo textual donde los jóvenes interactúan. Hay allí una negociación e intercambio textual de enunciados extraídos de canciones, lecturas, conversaciones con sus pares y de los medios masivos de comunicación. No existen estudios que analicen en profundidad estos textos, pero es posible asegurar que allí existe una importante fuente de información del conocimiento de sí mismos, en relación con la lectura y el conocimiento de textos. Una de las preguntas de este conjunto de reflexiones es precisamente la contribución de la lectura y la producción de textos en el conocimiento de sí mismos. Obsérvese el siguiente testimonio:

Muchos chicos y chicas, sin ser precisamente grandes lectores, han encontrado así, un día de su infancia o adolescencia, una historia, algunas páginas, que les han llevado a comprender que existía otra cosa, y que podían volverse parte activa de su propio devenir y del devenir del mundo que los rodea. Y todo eso gracias a la apertura de lo imaginario, gracias así mismo al acceso a una lengua diferente de la que sirve para la designación inmediata o para el improperio, gracias al descubrimiento, esencial, de un uso no inmediatamente utilitario del lenguaje (Petit, 2001).

Este y otros testimonios resultan suficientes para plantearse la siguiente pregunta: ¿cuál es el papel de la lectura y la escritura en el conocimiento de sí mismo, y en la formación intrapersonal de los jóvenes? Numerosos mediadores en los procesos de formación de lectores afirman que el papel de las bibliotecas en la formación de niños y adolescentes es el de continuar y apoyar la formación escolar (Petip, 1999). Para estos bibliotecarios leer permitía compensar, en parte, la falta inicial de capital cultural legítimo, era una oportunidad de ponerse al corriente. Por ello examínese el siguiente comentario de la investigadora francesa y anteriormente mencionada:

Cuando se vive en los denominados "barrios sensibles", ¿cómo la biblioteca ayuda a resistir a los procesos de exclusión y a construir su derecho de ciudadanía? La biblioteca pública es un punto de apoyo crucial en las estrategias de continuación o reanudación de los estudios; un foro informal, donde se esbozan nuevas formas de sociabilidad; un lugar que da acceso a lecturas que ayudan a elaborar una identidad singular, a llegar a ser un poco más sujeto de su destino, y no solamente objeto del discurso de otros; $y$, finalmente, en algunas ocasiones, una fuente de informaciones sobre temas políticos, que puede mantener un deseo de inscripción ciudadana (Petit, M. 2002).

Cuando los jóvenes se aproximan al mundo del libro y la lectura, lo hacen porque en ella descubren la posibilidad de encontrarse con enunciados en donde es posible confrontarse a sí mismos. La presentación de esta motivación por la lectura y la producción de textos no son asumidas con regularidad en la escuela, siendo su naturaleza generadora de motivaciones intrínsecas hacia la lectura. Las investigaciones sobre la motivación a los hábitos lectores apenas comienzan a hacerse evidente en este objeto de reflexión. La lectura les resulta trascendente, es ante todo por que les permite descubrirse o construirse, darle forma a su experiencia, reconstruir su sentido (Petit, M. 2002).

Al llegar a este punto, se podría afirmar que la lectura y la escritura como recurso para la formación emocional de los seres humanos han llamado la atención de muchos investigadores, ellos han señalado su importancia y trascendencia. Pero siguen siendo escasos la información 
y el seguimiento investigativo en el sentido de ubicar las contribuciones específicas del intercambio textual en adolescentes, si asisten sistemática o esporádicamente al mundo del libro.

\section{Los recursos del control emocional}

En el contexto de la comprensión y la producción textual existen un conjunto de habilidades de naturaleza psíquica que benefician y facilitan los propósitos de quienes leen y escriben. Hacer evidente dichas habilidades, describirlas, saber cómo se utilizan en la extracción de conocimientos de los textos, y en beneficio de una mayor eficiencia en la comprensión y producción textual, se constituye en un saber valioso para manejar con eficiencia los recursos del control emocional en beneficio de los objetivos de lectura y escritura. Cuando un estudiante universitario se sienta a leer o escribir, lo hace en un contexto específico, con unos recursos que le van a facilitar la construcción o modificación de unos textos existentes en su conciencia. Él es un sujeto activo que sabe moverse y aprovechar en su beneficio el intercambio enunciativo que se establece en los procesos de lectura y escritura.

Aquí es prudente plantear algunas preguntas:¿cómo operan los mecanismos de control emocional en los procesos de lectura y escritura? ¿Qué hábitos negativos han formado los estudiantes al leer $y$ escribir? ¿De qué manera enseñamos su desarrollo dentro de las aulas escolares y fuera de ellas? ¿Qué pasa emocionalmente cuando leemos y escribimos?, y ¿cuáles son las consecuencias de no contar con los recursos del control emocional en los procesos de lectura y escritura?
En el seguimiento a las preguntas formuladas con anterioridad, varios investigadores han constatado una serie de usos inadecuados del pensamiento a favor de la generación de textos, es decir, "en cierto sentido creamos un mundo y nos encerramos en él. Vivimos enfrascados en un mundo interior interminable donde la realidad externa no siempre tiene entrada" (Riso W, 2004). En muchas ocasiones resulta sorprendente que diversas personas reconozcan en la lectura una fuente de conocimiento y crecimiento personal, pero señalan que son muy poco constantes en la lectura y que los textos académicos no los entretienen, no encuentran placentero el hallazgo de nuevos conocimientos. Consecuencia de ello, abandonan la lectura porque no logran entender sus contenidos y reconocen sin vacilaciones que la escritura es una actividad de la que se sienten excluidos.

En estos casos, exigen de sus maestros una orientación previa sobre lo que se debe buscar en el texto, ya que consideran una pérdida de tiempo, argumentos que ofrece un autor para llegar a una conclusión. Se pretende manejar un mínimo de información, lo menos problemática posible y aplicable a muchos contextos. Este grupo de lectores quieren aprender una lectura rápida y cómoda, en la cual, con leer los titulares basta, solo se interesan por leer las condensaciones que en pocas palabras sintetizan los contenidos de un artículo.

Las siguientes son algunas justificaciones y explicaciones desde el punto de vista del control emocional que pueden aportar conocimientos y orientar sobre una mayor eficiencia en el uso de estos recursos mentales en beneficio de la lectura como fuente de nuevos conocimientos. Muchos estudiantes 
confiesan que suelen abandonar la lectura ante la presencia de conceptos y vocabulario desconocido. Daniel Cassany evidencia el problema y desarrolla un artículo que aparece en Colombia en 1999:

Uno de los problemas habituales al que deben enfrentarse los aprendices que se inician en la lectura es la presencia reiterada en los textos de palabras nuevas o desconocidas que dificultan la comprensión del contenido del escrito [...] Estos tienden a concebir este hecho como una circunstancia accidental y personal, causada por su limitado dominio de determinados registros de la lengua, por su pobreza de vocabulario o por la dificultad intrínseca que tienen los escritos. Ven las palabras desconocidas como 'extrañas', 'raras' y 'difíciles', como un obstáculo ineludible que impide acceder a la información contenida en el texto (Cassany1999).

Estas acciones no exitosas tienen como antecedente básico el hecho de que no es la primera vez que les ocurre $y$, ante la reiteración continua de este hecho, reconocen su incapacidad generando una renuncia y una exclusión con la que sus prácticas académicas se ven sometidas a esa limitación. El intercambio lexical es apenas una consecuencia de la vida en que nos encontramos; se introducen palabras nuevas, vocablos técnicos, palabras extranjeras, modismos que son asumidos por ellos sin dificultad aparente y con velocidad apenas perceptible. La velocidad con que se procesa la información en los medios de comunicación en el ejercicio de su competitividad pasa factura dejando hábitos que son incompatibles con los requerimientos que la construcción de textos en la escuela reclama y exige en la universidad. La lectura académica exige: reconocer, registrar, inspeccionar, mostrar, explorar, ejemplificar, aplicar y una palabra contextualizar los contenidos para que los enunciados conquisten y lleguen a las comunidades de indagación y sean procesados en nuevos textos

El manejo eficiente de los recursos del control emocional en una nueva lectura plantea siempre una reconstrucción significativa de los enunciados. Los lectores avezados asumen sin dificultad esta tarea, reconociendo en este hecho una actividad estimulante en la que muestra aportaciones que deja la lectura. Es cierto que todos los escritos tienen palabras claves. Pero es la totalidad del texto leído él que les asigna esa economía dentro del escrito (Martínez 1998). Los lectores con experiencia, suelen hacer una lectura general, más o menos rápida con la cual se forman una imagen del sentido general del texto. Los lectores inexpertos consideran que si no conocen la totalidad de las palabras con las que se construyó un escrito este es imposible de interpretar. Su lectura avanza palabra por palabra decodificando cada una de los conceptos del texto. Si acuden al diccionario además de la interrupción, incurren en el peligro de asumir una acepción demasiado general o diferente a la ofrecida en el texto, lo que aumenta las dificultades y el sentimiento de frustración.

Claro que esto no lo explica todo, estos lectores solo saben leer palabra por palabra, de otra manera les resulta difícil iniciar los procesos interpretación textual. No poseer una visión general del texto, más bien puede aumentar las dificultades, al acumular los significados sin establecer relaciones que solo puede dar la totalidad del texto. No tienen la malicia y la experiencia que les permite reconocer las marcas que los autores aportan en la construcción textual. Sin los recursos del control emocional que con- 
vierta las dificultades cognitivas en oportunidades para la generación de nuevos sentidos. Que haga de la perseverancia en la lectura, una fuente de confianza, y los nuevos conceptos en nuevos textos en donde se complementen y transformen los enunciados presentes en la conciencia del lector, porque no es posible ser eficiente lector y productor de nuevos textos.

\section{La auto motivación}

Veamos ahora el tercer concepto de la presente exposición, la motivación o mejor el recurso de la automotivación para el desempeño de una tarea específica, leer y escribir. Las diferencias entre grupos, en la conquista de un objetivo común, se explican a partir de la motivación vinculada con la tarea encomendada. Cuando una persona compara su comportamiento emocional frente a la consecución de un propósito, más o menos semejante, encuentra que las motivaciones eran diferentes. Los motivos con que se ejecutan las acciones determinan la calidad, el sentido y la eficacia de las mismas. La motivación de la lectura y de la escritura establece diferencias en la eficacia y en la profundidad con las que se asumen la producción de nuevos textos.

La lectura y la escritura han sido planteadas como actividades vinculadas al estudio y a la formación académica, indispensables en las tareas de formación en muchos dominios de la modernidad. El aprendizaje de la automotivación tiene lugar en un intercambio textual en contextos específicos. Por ello en la comprensión y la producción textual, se requiere de constancia, perseverancia y tenacidad creciente, todo esto en el contexto en el que aprende y se desempeña. Cada vez que el estudiante avanza en la comprensión de unos textos aparecen otros más complejos -solo en la penumbra se ven las luces más sutiles-, pues cada que se precisa ampliar el conocimiento de un fenómeno o proceso hay que enfrentarse a construcciones enunciativas más complejas. Sólo cuando el lector o escritor sabe conducir su motivación es posible reconocer un camino prometedor.

En este sentido, la auto motivación en el ejercicio de la lectura y, con mayor énfasis en la escritura, no puede lograrse sin las actividades que configuran la conquistas de nuevos textos, porque en ellos se evidencian la producción de nuevos conocimientos con los cuales se contribuye como interlocutor válido en las comunidades académicas, científicas o culturales.

Los alumnos que abrigaban muchas esperanzas, se fijan metas más elevadas y saben cómo trabajar arduamente para alcanzarlas. Cuando se comparan los logros académicos de los alumnos que poseen aptitudes intelectuales equivalentes, lo que les distingue es la esperanza (Snyder, C.R, 1991).

La anterior constatación nos lleva a entender que la auto motivación en la lectura y la escritura es uno de los recursos emocionales que la investigación educativa debe asumir, para brindar a los mediadores ${ }^{1}$ un conjunto de herramientas que faciliten el trabajo en la formación de lectores y productores de textos. Identificar sus componentes, la forma en que están organizados, las relaciones que contraen entre sí haciéndose operantes y la manera como se aprende y desarrolla este recurso emocional, constituye el propósito del siguiente apartado.

1. Educador, en el sentido otorgado por Vigosky, en Pensamiento y lenguaje (Autor: faltan demás datos de la obra, favor completar). 


\subsection{El concepto de motivación}

Este concepto aparece en diversos estudios, en áreas de investigación en psicológica educativa y empresarial. En estas reflexiones, se reconocen la existencia del concepto y realizan aportaciones en diferentes concepciones. En este apartado, se tendrá en cuenta que se trata de un conjunto de procesos implicados a la estructura emocional del sujeto que presenta tres dimensiones: 1) activadora, b) creativa, c) directiva y persistente sobre el comportamiento en una actividad específica del sujeto.

En la primera dimensión, la activadora, a pesar de la extensa discusión epistemológica nos ubicamos en el campo cognitivo porque interesa el concepto como herramienta que facilita la comprensión y la producción textual y su implementación dentro del aula escolar. Para que unas personas muestren motivación por la lectura y la escritura y se esfuercen de manera continuada, tratando de obtener resultados positivos en éstas, es necesario que se les propongan unas metas que influyan positivamente en su comportamiento. Aquí reconocemos la faceta activadora, pues en ella se percibe la lectura y la escritura como una forma de llegar al conocimiento.

Siguiendo con lo planteado existen una serie de reflexiones que orientan la búsqueda de conceptos implicados en esta reflexión, señalando que hay dos clases de motivaciones extrínsecas e intrínsecas. En la motivación extrínseca se proponen metas externas a la tarea que deben realizar; por ejemplo: los premios y los castigos son reforzadores externos, ellos presentan limitaciones que hay que tener en cuenta a la hora de aplicarlos, sin embargo en algunas ocasiones se muestran eficaces en la práctica educativa. Pero, es la motivación intrínseca la que resulta más sólida en todas las etapas del desarrollo cognitivo. La lectura y la escritura presentan elementos activadores a partir de la tarea. Obsérvese un ejemplo muy ilustrativo en la siguiente oración:

Un conejo se quedo dormido y cuando despertó no tenia sus orejas.

En el ejemplo presentado, la estrategia de motivación nace del propio texto, en el cual las lógicas narrativas invitan al lector ha reconocer cómo perdió sus orejas el conejo y la forma en que las recuperó. En este sólo enunciado, se concretan allí, muchas variables de creatividad en las cuales aparece cierta emulación imaginativa y exageraciones que desbordan el contexto inicial de la historia. Descubrir la forma y los recursos empleados por un grupo de niños de ocho años es un ejercicio altamente motivador y generador de creatividad. Este ejercicio desarrollado con estudiantes de 12 escuelas del Distrito de Agua blanca en Cali muestra la activación en las diferentes orientaciones que pueden tener, la motivación, la importancia y el gusto por la persistencia en la lectura y la escritura. Es evidente que se requiere cierta continuidad en los diferentes niveles de escolaridad y en distintos géneros discursivos. La generación de ambientes creativos y competitivos dentro del aula de clase hace que los estudiantes se esfuercen por presentar soluciones a un relato.

En este mismo sendero argumentativo, otras estrategias en escritura resultan eficaces como la aprensión de la descripción de objetos en los que se combinan las características físicas, químicas, psicológicas o ambientales de un proceso. O también la estrategia de la exposición o demostración 
de una teoría, por ejemplo: "la materia al igual que la energía ni se crea ni se destruye sino que se transforma", resulta de gran utilidad y eficacia. En la construcción de textos argumentativos es posible generar, en el aula de clase, una especie de emulación argumentativa, partiendo de cualquier tesis en la que sabemos, desde la lógica de Aristóteles, que toda tesis es una proposición que requiere ser argumentada.

Queremos dejar claro, ante los lectores, que en la dimensión directiva, el aprendizaje de la automotivación esta asociada al desarrollo de recursos metacognitivos que nacen en la naturaleza de los textos. Como son la extracción de conceptos, su comparación, el contraste con otros textos, la comparación de argumentos, su organización según diferentes criterios como su aparición, importancia, ubicación en determinada concepción o escuela o la explicación y calificación del argumento desde la axiomática que lo origina. Tal es el caso de disciplinas científicas como la resistencia de materiales en Ingenierías, en donde la dimensión directiva resulta muy elocuente para la aprensión de la parte cualitativa. Otro caso puede ser el de la morfología en los textos de salud, la cual desarrolla en los estudiantes un metalenguaje generador de argumentos con gran capacidad de significación.

Para la reflexión de la persistencia como ejercicio de la motivación existe una exploración desarrollada en los Estados Unidos y en Australia en donde la motivación por la lectura y la escritura a partir de pares ha dado resultados que llaman poderosamente la atención en los dominios de la lectura y la escritura. La motivación entre pares es un espacio de reflexión muy escasamente trabajado en nuestro medio. La motivación generada en esta estrategia didáctica hace que los estudiantes lean y escriban con más eficiencia, vinculando su trabajo a consultas más personales, al reconocimiento de problemas, la afirmación de estrategias metacognitivas y la vinculación de los recursos de la lectura y la escritura al mejoramiento de la autoestima y la autonomía escolar.

\section{La empatía}

En el camino iniciado corresponde ahora el concepto de empatía. En varios textos en los cuales se realizan reflexiones sobre inteligencia emocional, se reconoce la empatía como la comunicación emocional por canales no verbales (Goleman, 1995). Este concepto ocupa una economía muy trascendente dentro del conjunto de textos de quienes se acercan a estos temas porque define el fin más importante de la inteligencia emocional. La empatía hace que seamos felices y responde a las expectativas de la búsqueda de sus investigadores cuando afirman que la inteligencia emocional sirve para vivir con calidad de vida.

Cuando se intenta relacionar los elementos de Inteligencia emocional con los procesos de lectura y escritura, se encuentran hallazgos que abren varias preguntas de investigación y otras que ya habían sido planteadas en el pasado, pero que ahora cobran una dimensión muy novedosa: ¿Cómo se experimenta la empatía? ¿Cómo es un proceso de comunicación emocional por canales no verbales en los procesos de lectura y escritura?

Estas preguntas son muy complejas y parecen salidas del contexto porque es posible participar e intervenir procesos, en un lugar donde no tiene lugar el texto. $Y$ es precisamente allí donde nace y se encuen- 
En la escritura es también posible admitir la presencia del estado de flujo aunque su descripción no es tan frecuente como en la lectura, pues se debe introducir en el itinerario de trabajo, desde las disciplinas, porque la escritura es la mejor expresión de saberyel dominio de todas las disciplinas y el aprendizaje de la pasión en una disciplina. tra la respuesta. La empatía aparece en el texto en el momento, en el que, al que lee, se le olvida que está leyendo, y todas sus emociones se canalizan y se orientan en el disfrute textual tan intenso que se olvida que el texto existe.

Uno mismo se encuentra en un estado extático hasta el punto que se siente que casi no existe. He experimentado esto una y otra vez. Mi mano parece desprovista de mi propio ser, y yo no tengo nada que ver con lo que esta sucediendo. Simplemente me quedo sentado, en un estado de admiración y desconcierto y todo fluye por si mismo (Csikszentmihalyi, 1975)

Esta descripción de un estado emocional es conocida como "estado de Flujo" y suele presentarse en muchas actividades y en diversas personas como deportistas de alta competencia, jugadores de ajedrez, artistas, maestros y como todos sabemos en lectores y escritores. El estado de flujo no sólo es un estado de felicidad en diversas actividades, sino que en este estado se alcanza la óptima eficiencia en el desempeño propuesto. Los trabajos de la psicología de las experiencias óptimas han hecho indagaciones sobre la existencia de este estado en muchas personas y se han interesado no solo por lo que sienten las personas, sino cómo lo logran Por ello es importante preguntarse cuáles son las circunstancias contextuales que condicionan su existencia, y en materia de lectura y escritura es absolutamente pertinente preguntar ¿de qué forma podemos proponer su aprendizaje?

Continuando con la anterior idea, la exploración del estado de flujo es un incentivo determinante en la búsqueda del desempeño y el aprendizaje porque generan una serie de prácticas y recomendaciones para el aprovechamiento de la atención y el interés para desarrollar muchas actividades, entre ellas la lectura y la escritura. Los deportistas de alta competencia lo reconocen en diversas disciplinas como la "zona". La empatía consiste en saber asumir todas las emociones, canalizarlas y hacerlas positivas en torno a la tarea que se está desempeñando en ese momento.

Debido a lo anterior, resulta evidente que la educación requiere de docentes con gran capacidad de motivación. La descripción de estado de flujo es "el hecho de sentirse completamente comprometido con la actividad por sí misma. El ego desaparece. El tiempo vuela. Toda acción, movimiento o pensamiento surgen inevitablemente de la acción, del movimiento y del pensamiento previo, es como si estuviéramos tocando jazz. Todo tu ser está allí, y estás aplicando tus facultades al máximo" (Goleman, 1995). Hoy en medio del escepticismo en el que nos ha sometido la competitividad oficial, en su falacia de oferta educativa por demanda, es propicio pensar en la posibilidad de enseñar la pasión por la lectura y la escritura.

En la escritura es también posible admitir la presencia del estado de flujo aunque su descripción no es tan frecuente como en la lectura, pues se debe introducir en el itinerario de trabajo, desde las disciplinas, porque la escritura es la mejor expresión de saber y el dominio de todas las disciplinas y el aprendizaje de la pasión en una disciplina. Pero también es posible reconocer otras aplicaciones de la empatía en la comunicación escrita que así mismo, es posible reconocer en la lectura.

El diccionario define la empatía como "capacidad o proceso de penetrar profundamente a través de la imaginación, dentro 
de los sentimientos y motivos del otro" (Diccionario Español, 1995). En un sentido menos académico, implica ponerse "en los zapatos o en la piel del otro", de manera que se pueda sentir realmente sus penas, sus temores, o más positivamente hablando, sus alegrías y motivaciones. La capacidad de ejercitar la empatía sirve a lectores y escritores para ubicar la posición del receptor y el emisor tanto en escritura como en lectura, demostrando que lo conoce, que tiene en cuenta su punto de vista, sus intereses, necesidades y sentimientos, y ese conocimiento y su sensibilidad deben ser recogidos en el texto. La verdadera empatía es la que consigue el emisor cuando se olvida de sí mismo y habla al receptor como éste desea ser hablado en ese preciso momento.

Así pues, la empatía conduce al lector dentro del texto y orienta los sentidos que se significan en él al tener sintonía emocional con los lectores o escritores por muy académicos que sean los escritos. Los lectores universitarios no tienen por qué renunciar a la función emotiva en el ejercicio de la lectura y la escritura, a ninguna de las funciones del lenguaje y si se profundiza en el concepto objeto de reflexión, se advierte que la empatía como elemento de la inteligencia emocional, acerca y resuelve muchas inquietudes en todas las funciones del lenguaje, en los dominios de la comprensión y producción textual desde todas las disciplinas; Porque la ampatía impregna todas las funciones del lenguaje mejorando sustancialmente la calidad del sentido dispuesto en el texto leído o escrito.

\section{Inteligencia interpersonal, lectura y escritura}

La convivencia humana se hace vigente en el intercambio textual. Ella nace y se hace en la conversación. Este es el lugar donde se originan y se consolidan los acuerdos. El lenguaje es producto de los acuerdos conductuales consensuales (Maturana, 1998). Los textos y su circulación son la forma más general de hacer ejercicio de la inteligencia interpersonal, ella se desarrolla en muchas producciones textuales en el seno del grupo en el cual convive, ocupando especial atención a los acuerdos que siempre son textos y, en cuya economía semiótica, hace su enunciación un asunto vigente en la construcción de nexos sociales.

Teniendo en cuenta el párrafo anterior, el concepto de inteligencia interpersonal se hace operante entre personas que están físicamente próximas. Cada una de las ellas produce comunicaciones que son una respuesta a los mensajes que han sido elaborados por la otra o las otras personas implicadas en la conversación. La capacidad para reconocer textos y generarlos de manera pertinente hace que como sujetos se tenga aceptación en el seno de un grupo en el cual se convive.

La inteligencia interpersonal es definida en los textos generados en torno a los textos enunciados por los hablantes como una facultad humana que se configura en los términos de Goleman (1995) en los siguientes enunciados

Las relaciones interpersonales alimentan permanentemente la convivencia entre pares y es la comprensión y la generación de los mismos los que determinan la calidad de los estados de convivencia y la capacidad de trascendencia del sujeto en los grupos en los que convive (Goleman, 1995).

La capacidad de leer las emociones y los sentimientos del otro y comunicar su naturaleza en enunciados y pensamientos tiene que ver con la forma y la manera como los
La capacidad de ejercitar la empatía sirve a lectores yescritores para ubicar la posición del receptoryel emisor tanto en escritura como en lectura, demostrando que lo conoce, que tiene en cuentasu punto de vista, sus intereses, necesidades $y$ sentimientos, yese conocimiento $y$ su sensibilidad deben ser recogidos en el texto. 
sujetos son formados en lectores y productores de textos. La producción y confrontación de textos en comunidades hace que su enciclopedia cultural acumule textos desde los cuales interpreta, especialmente, los que producen los demás, trascendiéndolos con aportaciones y al asumirlos con la capacidad de cuestionarlos críticamente, aportando al grupo nuevos textos .

De estas y otras páginas que circulan entre las comunidades académicas, resulta que un desempeño social determinante en el crecimiento personal del sujeto es la capacidad de expresar sus sentimientos y emociones en el grupo en el que se inscribe y se sustenta. Qué sentimientos muestran, la forma como se hace este desempeño social, a quiénes y de qué manera se comunican en el camino sinuoso en el cual se incorpora a la enciclopedia cultural. Todas estas son competencias que se expresan a través de textos que es necesario producir para sustentar la naturaleza de la convivencia y la fortaleza del grupo en el que se convive (Ekman y Friesen, 1975). Los textos causan diferentes reacciones de aceptación, indiferencia, se ridiculizan o se asumen con ternura, de acuerdo con la factura de donde provengan y el contexto social o afectivo que los ha condicionado.

\section{A manera de conclusión}

En las producciones discursivas que tienen presencia en la universidad, se combinan lenguajes provenientes de varios grupos que suelen ser en el caso de Colombia, una síntesis de lo etnográfico, lo cultural, grupo de pares, extractos sociales y marginales. En estas mezclas se sintetiza lo virtual con lo grupal en las circunstancias contextuales en que las que la emisión de enuncia- dos tiene lugar en diferentes eventos de la comunicación, formales e informales.

En el caso de la construcción de textos académicos, en el contexto de la educación superior, los estudiantes tienen problemas en todos los niveles como es la comprensión literal de muchos conceptos, enunciados y argumentos por la falta de experiencia directa en su intercambio. Otro nivel es el interpretativo que no alcanza los niveles de intertextualidad por que los textos con los que se confrontan sus escritos, simplemente no compaginan con los que circulan en sus núcleos de convivencia obligándolos a disociar lo académico de la cotidianidad, operación que hace que los aprendizajes no resulten significativos y con poca distancia critica.

Uno de los casos, muy pertinentes en lo académico, es el ejercicio de la intertextualidad. No se asume en una confrontación lícita que involucre el lenguaje del grupo en el cual se convive trascendiendo su lenguaje, sino que las enunciaciones académicas, resultan extrañas $y$, en algunos casos, son factor de aislamiento y ruptura en la trascendencia enunciativa dentro del grupo en el que se convive. Aquí opera una disociación en la que operan dos mundos que no se aportan ni se excluyen.

La oralidad asume permanentemente constantes innovaciones en todas las funciones del lenguaje, a partir de las situaciones en las que se expresan los contextos en los cuales se significan los mensajes con éxito, asegurado dentro del grupo que las hace circular y las sustenta, y con muy escasas incursiones en la enunciación escrita. La enunciación académica no los contempla, y con muy pocas ocasiones los consulta y los tiene en cuenta.

La sociedad pasó de la cultura de la expresión oral a la radio y, de allí, la televi- 
sión ganó un proceso, pues la cultura del libro no se desarrolló en Latinoamérica, al contrario de lo que ocurrió en Europa y Estados Unidos. La cultura escrita solo trascendió en pequeños círculos académicos y culturales que tenían acceso al texto impreso.

Es frecuente escuchar entre docentes la siguiente expresión "los estudiantes escriben como hablan”. Esta apreciación de muchos colegas es explicable en términos de lo que se practica y la forma como se desarrollan los textos y su intercambio en la inteligencia interpersonal. La cultura escrita es muy escasa, ella está más bien vinculada al castigo. Los estudiantes reclaman diciendo " ¿ qué te hemos hecho para que nos hagas escribir tanto?”. Los estudiantes y muchos docentes ven la posibilidad de la escritura como una actividad que en la mayoría de los casos, por decir lo mínimo, es muy poco frecuente. Si se pretende que los estudiantes escriban claro, los docentes debemos ser claros en la formulación de los enunciados y especialmente en los que aparece la tarea y las actividades con las que se configura un escrito académico. Saber que va a ser evaluado y cómo va a ser valorado, constituyen los minutos de clase en los cuales es muy conveniente hacer una labor de recordación permanente. El diseño de la evaluación se realiza en el momento en que se formulan los objetivos.

Es indudable que en el ejercicio del desarrollo humano, los textos de diversos investigadores en torno a la inteligencia emocional hacen aportaciones que se confrontan en diferentes círculos académicos y de indagación. La vinculación de los procesos de lectura y escritura plantean muchas preguntas de investigación que con el tiempo y la experimentación, en el aula de clase, deberán contribuir a formar más eficientes lectores y productores de textos.

\section{Bibliografía}

1. Aussubel, D., Novak, J. y Hanesian, H. (1989). Psicología Educativa. 2 ed. México: Trillas.

2. Beaudegrande, C. y Dessler, M. (1981). Introducción a la lingüística del texto. Barcelona: Ariel.

3. Bourdieu, P. y Passeron, J.C. (1998). La reproducción: elementos para una teoría del sistema de enseñanza. Tercera Edición, México: Fontamara.

4. Càrate, M. (1994). La comprensión de cuentos en los niños. Siglo Veintiuno de España Editores. S.A.

5. Campos, M. y Gaspar, F. J. (2001). Las relaciones textuales. Madrid: Morata.

6. Cassany, D. (1994). ¿Cómo se aprende a escribir? Barcelona: Paidós.

7. Cassany, D. (1998). Reparar la escritura. Barcelona: Grau.

8. Cassany, D. (1999). Construir la Escritura. Barcelona: Paidós.

9. Ferreiro, E. (2000). Pasado y presente de los verbos leer y escribir. México: Fondo de Cultura Económica.

10. Gaardner, H. (1995). La teoría de las inteligencias múltiples. Barcelona, Paidós.

11. Goleman, D. (1995). Inteligencia Emocional. Vergara editores. Bogotá. 
12. Habermans, J. (1980). Teoría de la acción comunicativa. Madrid: Taurus.

13. López, G. S. (1998). Metacognicion y procesos de lectura. Cali: Escuela de Ciencias del lenguaje.

14. Martínez, M. C .(2002). Lectura y escritura de textos. Cali: Escuela de Ciencias del Lenguaje.

15. Maturana, H. (1998). El sentido de lo humano. Santiago de Chile: Dolmen Editores.

16. Patterson, K. (1999). Medical Research Council Cognition \& Brain Sciences Unit Cambridge.

17. Petit. M. (2006). Lecturas: del espacio íntimo al espacio público. México: FCE.

18. Petit, M. (2001). Elogio del encuentro. En: Lecturas: del espacio intimo al espacio público. México: Fondo de Cultura Económica, 2001.

19. Petit, M. (2003). Pero, ¿Qué buscan nuestros niños en sus libros? Bogotá: CONALECTURA

20. Petit, M.(1999). Tercera jornada. El miedo al libro. En Nuevos acercamientos a los jóvenes y la lectura, pp. 107-152. México: FCE. (Espacios para la lectura).

21. Thomas, G. y Loxley, A. (2001). Deconstructing special education and constructing inclusion. Buckingham: Open Univesity Press.

22. Van Dijk, T. (.1986). La ciencia del texto. Bogotá: Editorial siglo XXI.

23. Vigosky, L. (1970). El desarrollo de procesos psicológicos superiores. Barcelona:Crítica. 